\title{
Surya dalam Berita
}

\author{
Santi Indra Astuti
}

ABSTRACT

\begin{abstract}
For sure, Surya Paloh is a political figure prominent enough in Indonesia. As one of important member of Golkar, Surya Paloh famously known as the leader who often made manouvres-many of them considered as unpopular decisions for his party-mate. He often use his media-Metro TV and Media Indonesia (daily newspaper)— to support his political career. An analysis of Surya Paloh's news in his daily become the evidence of this hypotheses. Surya Paloh depicted here with the newsmaker, from Sultan to Presidents and other political leaders. Media Indonesia, therefore, has framed Surya Paloh as one of the newsmaker to be considered in national politics.
\end{abstract}

Kata kunci: Surya Paloh, Media Indonesia, analisis berita.

Objektivitas dan netralitas pers adalah kode sakral yang tampaknya tak bisa ditawar lagi dalam diskusi seputar profesionalisme pers. Komisi Hutchins, atas dasar premis tersebut, jauh-jauh hari sejak 1945, telah menetapkan serangkaian kode etik jurnalistik yang menekankan pentingnya jurnalis bersikap netral dan mempertahankan objektivitasnya. Kini, menjelang pemilu berlangsung, tekanan agar pers bersikap objektif dan netral tampak semakin menguat. Ini mengingat pemilu merupakan ajang pelbagai kepentingan, sementara pers, di lain pihak, merupakan medium tempat bertemunya pelbagai kepentingan tersebut.

Hukum komunikasi massa yang berwawasan public responsibility mengharuskan pers bersikap netral. Alasannya, pers adalah wujud dari public sphere, ruang publik, yang tak boleh dicampuri kepentingan apapun atau diintervensi oleh pihak manapun yang mengatasnamakan kepentingan publik. Masalahnya, pers ternyata tidaklah sesteril itu. Ketika memasuki dunia industri, pers dituding membawa kepentingan-kepentingan ekonomi kapitalisme-alih-alih membawa kepentingan publik. Tatkala tokoh-tokoh kunci dalam dunia politik datang menguasai pers, maka pers-pun disinyalir membawa kepentingan-kepentingan politis yang mengganggu independensi dan kemurnian ruang publik.

Bagaimana dengan situasi di Indonesia, khususnya ketika para politisi memasuki ruang publik yang digawangi pers, atau tepatnya, ketika pemilik media terjun ke dalam dunia politik? Dapatkah pers atau media yang dipimpinnya bersikap netral dan mempertahankan objektivitasnya? Tulisan berikut ini, melalui pendekatan analisis wacana sederhana, mencoba meneropong apa yang terjadi ketika seorang pemilik media menjatuhkan pilihannya untuk menjadi seorang politisi dan bertanding secara terbuka memperebutkan kursi (calon) kepresidenan. 


\section{Surya Paloh: Sang 'Presiden'}

Adalah Surya Paloh, tokoh yang mewakili karakter subjek yang dimaksud. Sebagai pemilik Media Group yang mewadahi harian Media Indonesia dan Metro TV, maupun sebagai anggota Partai Golkar yang aktif saat ini, Surya setidaknya memiliki dua identitas utama: anggota komunitas pers dan anggota komunitas politisi. Ada dua kepentingan yang dibawa Surya dalam identitas tersebut. Sebagai anggota komunitas pers, Surya membawa suara pers (yang idealnya bertugas mempertahankan eksistensi dan netralitas public sphere). Posisinya yang sangat dominan sebagai pemilik dua media besar berskala nasional juga turut menentukan kebijakan-kebijakan yang terkait dengan dunia jurnalisme. Di sisi lain, Surya tercatat sebagai anggota teras Partai Golkar. Bukan cuma itu, Surya juga tampil sebagai calon presiden Partai Golkar yang dikukuhkan dalam Konvensi Partai

\section{Tabel 1: Berita tentang Surya Paloh}

\begin{tabular}{|c|c|}
\hline Hari/Tanggal & Judul \\
\hline Sabtu, 24 Januari 2004 & Pers Harus Galang Solidaritas (hal. 1) \\
\hline & $\begin{array}{l}\text { Foto: Surya Main Gitar dalam Perayaan Ultah MI ke } 34 \text { (hal. } \\
\text { Dalam) }\end{array}$ \\
\hline Kamis, 29 Jan 2004 & Tidak Relevan Dikotomi Parpol Terhadap SARA (hal. 16) \\
\hline & Foto: Amien Rais dan Surya Paloh (hal. 7) \\
\hline & $\begin{array}{l}\text { "Media Massa Dunia Berperan Besar : Memerangi Penyebaran } \\
\text { AIDS" (hal. 24/Rubrik Kesehatan) }\end{array}$ \\
\hline & $\begin{array}{l}\text { Foto: Surya Paloh di tengah pemimpin media lain dalam diskusi } \\
\text { bersama PBB (hal. 24) }\end{array}$ \\
\hline Rabu, 11 Feb 2004 & Presiden Heran Terhadap Wacana Koalisi (hal. 1) \\
\hline & $\begin{array}{l}\text { Foto: Surya Paloh bersama tokoh pers nasional berbincang- } \\
\text { bincang dengan Presiden Megawati (hal. 1) }\end{array}$ \\
\hline Sabtu, 21 Feb 2004 & Surya-Sultan Adakan Pertemuan Tertutup (hal. 1) \\
\hline Selasa, 2 Maret 2004 & $\begin{array}{l}\text { Foto: Pemilik Media Group Surya Paloh berjabat tangan dengan } \\
\text { Susilo Bambang Yudhoyono dalam acara peresmian Grand } \\
\text { Studio Metro TV di Kedoya, Jakarta. Dalam acara itu } \\
\text { diluncurkan program The Election Channel Metro TV dengan } \\
\text { penandatanganan MoU Metro TV bersama } 5 \text { stasiun televisi } \\
\text { internasional. }\end{array}$ \\
\hline & $\begin{array}{l}\text { Berita: Metro TV Gandeng } 5 \text {...halaman } 1,1 \text { kolom, } 10 \text { paragraf } \\
\text { (4 paragraf opini Suryo. } 2 \text { paragraf Zsa Zsa Yusharyahya selaku } \\
\text { Dir Ops Metro TV, } 1 \text { paragraf untuk opini sejarahwan Anhar } \\
\text { Gonggong, sisanya adalah peristiwa) }\end{array}$ \\
\hline Jumat, 5 Maret & $\begin{array}{l}\text { Foto: Capres Versi Dunia Usaha (hal. 2, uk. 10x16.5 cm). Bos } \\
\text { Media Group Surya Paloh bercakap2 dengan Ketua Komite } \\
\text { Pemulihan Ekonomi Sofjan Wanandi. }\end{array}$ \\
\hline & $\begin{array}{l}\text { Berita: "Pengusaha Mampu Pimpin Negara" (hal. 16, } 8 \text { paragraf } 3 \\
\text { kolom) }\end{array}$ \\
\hline Senin, 8 Maret 2004 & Surya Diberi Gelar Tuanku Johan Pahlawan (hal. 17) \\
\hline
\end{tabular}


Golkar tahun lalu. Dengan kedudukan sepenting ini dalam partai Golkar, wajar saja jika tumbuh kecurigaan bahwa kiprahnya di media yang dipimpinnya tidak lagi netral, tetapi juga mengakomodasi kepentingan partai politik tempatnya bergabung, atau kepentingannya sendiri sebagai salah satu calon presiden Partai Golkar.

Untuk membuktikan benar-tidaknya dugaan tersebut, analisis sederhana berikut ini akan melihat bagaimana sosok Surya dikonstruksi oleh Media Indonesia, salah satu harian besar berskala nasional di Indonesia. Surya Paloh, di Media Indonesia, berkedudukan resmi sebagai Pemimpin Umum.

\section{Surya Paloh dalam Berita}

Berita yang dianalisis diambil dari harian $\mathrm{Me}$ dia Indonesia mulai tanggal 15 Januari hingga 10 Maret 2003. Tidak semua berita yang menyebut nama Surya Paloh diambil dalam analisis ini. Berdasarkan pertimbangan tertentu, hanya berita yang memuat Surya Paloh sebagai tokoh sentral sajalah yang diambil. Memang terdapat sejumlah berita lain yang menampilkan nama Surya Paloh. Namun, berita-berita semacam itu tidak turut dianalisis, karena sosok Surya Paloh tidak mendominasi isi pemberitaan.

Berikut adalah tabel berita yang dianalisis:

Tabel Berita tentang Surya Paloh

Jika disimak sekilas, berita-berita yang mengangkat Surya Paloh dalam tabel di atas tampil dalam tema yang beragam: politik, media, ekonomi, hingga budaya. Ini memperlihatkan dominasi Surya Paloh di berbagai bidang, sekaligus menunjukkan kerja media dalam mencitrakan Surya sebagai tokoh yang patut diperhitungkan di setiap bidang penting kehidupan.

Patut dicatat pula, Surya juga tidak cuma tampil dalam pemberitaan. Minggu kedua Maret, tepatnya 11 Maret 2004, Surya tampil dalam iklan launching program The Election Channel yang menggandeng 5 stasiun televisi asing, sebesar satu halaman penuh. Foto Surya termuat di sana, berukuran besar, dalam salah satu pose terbaiknya. Posisi Surya semacam ini secara semiotik dapat dibaca sebagai point of entry untuk memainkan petanda-petanda yang menokohkan Surya sebagai sosok yang sangat penting. Iklan ini dimuat setidaknya di tiga media massa nasional: Koran Tempo, Media Indonesia, dan Kompas.

Jadi, jika politikus lain tampil berkampanye di media massa dengan membawa suara dan atribut parpol masing-masing, Surya dengan cerdik memilih menokohkan diri sebagai tokoh 'apolitis' yang mengemban peran besar dalam dunia pers dan media. Politikus yang berkampanye atas nama partai hanya bisa mengikat khalayak media yang kebetulan menjadi simpatisan partainya. Dengan menampilkan diri dalam iklan yang sifatnya apolitis, Surya berkemungkinan memperluas dukungan dan simpati dari siapapun, tidak cuma simpatisan parpolnya saja. Dapatlah dibayangkan betapa besarnya publisitas Surya melalui iklan ini, menyertai berita-berita yang sebelumnya juga dirancang untuk mengonstruksi sosoknya selaku salah satu tokoh dominan di Indonesia.

\section{Januari: Surya, Presiden, PBB}

Pada bulan Januari 2004, Surya Paloh ditampilkan dalam 3 pemberitaan dengan tematema yang berbeda: tema menyangkut (kebebasan) pers, tema menyangkut pemilu (dalam judul "Tidak Relevan Dikotomi Parpol terhadap SARA”), dan tema tentang kesehatan dikaitkan dengan program pemberantasan AIDS yang diprakarsai oleh PBB (dalam judul "Media Massa Dunia Berperan Besar : Memerangi Penyebaran AIDS"). Dilihat dari judul dan temanya, memang hanya satu yang berkaitan dengan pemilu, yaitu berita kedua. Namun berita lain -kendati tidak terkait dengan pemilu - tetap akan dianalisis karena menempatkan Surya Paloh sebagai sosok yang dominan dalam isi pemberitaan, sehingga mempengaruhi konstruksi pesan media tentang subyek yang diberitakan.

Mengenai penempatan berita, berita tentang solidaritas pers ada di halaman 1 , berita tentang parpol dan isu SARA di halaman 16, adapun berita tentang kesehatan ada di rubrik "Kesehatan" di halaman 24. Penempatan berita di halaman 1, jelas merupakan keputusan yang sangat strategis - kita semua tahu bagaimana ajaibnya kekuatan halaman 
pertama dalam menarik perhatian pembaca. Penempatan berita tentang parpol dan isu SARA di halaman 16, juga bisa dibaca sebagai langkah yang strategis, karena halaman 16 berada di tempat paling belakang dan hanya berbeda dengan halaman 1 karena lipatan saja. Baik berita di halaman 1 maupun 16, sama-sama berada di kulit luar, yang merupakan tempat istimewa untuk menarik perhatian pembaca. Berita Surya di New York, kendati berada di halaman dalam (hal. 24), tetap saja istimewa. Berita tersebut mendominasi halaman yang diperuntukkan bagi rubrik "Kesehatan". Teks maupun foto, nyaris makan tempat setengah halaman. Foto Surya bersama para pemimpin dunia lainnya mendominasi halaman tersebutberukuran besar: $12 \times 20 \mathrm{~cm}$ (bandingkan dengan foto lain yang ukurannya tak lebih dari setengahnya).

Satu hal yang menarik adalah mencermati bagaimana Surya tidak cuma ditampilkan dalam teks, tapi juga dalam foto. Ketiga berita tentang Surya Paloh di bulan Januari kesemuanya disertai dengan foto: foto Surya sedang main gitar dalam perayaan HUT Media Indonesia ke-34 (menyertai berita "Pers Harus Galang Solidaritas", foto diletakkan terpisah dari berita), foto Surya sedang duduk bersama Amien Rais ketika Ketua Umum PAN tersebut mengunjungi markas harian Media Indonesia (menyertai berita "Tidak Relevan Dikotomi Parpol Terhadap SARA," lagi-lagi foto diletakkan terpisah dari beritanya), dan foto Surya sedang duduk bersama para pemimpin media massa negara lain dalam diskusi bersama PBB di New York untuk membahas peran media dalam membantu program PBB memerangi AIDS (menyertai berita "Media Massa Dunia Berperan Besar: Memerangi Penyebaran AIDS"). Keputusan meletakkan foto secara terpisah dari beritanya kemungkinan memang karena alasan keterbatasan tempat. Tapi di sisi lain, kebijakan ini juga bisa dibaca sebagai langkah strategis untuk memperpanjang tempat bagi pemberitaan tentang Surya Paloh. Jika foto ditempatkan sehalaman dengan beritanya, usai membaca berita, pembaca tidak akan menemukan lagi sosok Surya Paloh. Dengan menempatkan foto Surya di halaman dalam, atau halaman terpisah dari berita utamanya, maka pembaca kemungkinan besar akan lebih banyak lagi diterpa dengan sosok Surya.

\section{Februari: Surya dan Sultan}

Pada Februari, berita maupun foto Surya Paloh tampil dua kali: berita berjudul "Presiden Heran Terhadap Wacana Koalisi” (Rabu, 11 Feb 2004) dan berita berjudul "Surya-Sultan Adakan Pertemuan Tertutup" (Sabtu, 21 Feb 2004). Kedua berita diletakkan di halaman pertama, dan keduanya menampilkan foto.

Dalam berita pertama, isi pemberitaan pada intinya mendeskripsikan tanggapan Presiden Megawati terhadap wacana koalisi yang dilontarkan sejumlah politisi, yang menurut Mega tidak relevan untuk pemilu. Kendati demikian, Surya muncul pada bagian terakhir, menempati satu subjudul tersendiri. Isi subjudul itu tidak terkait dengan wacana koalisi, namun berisi fakta peristiwa dan fakta opini (dari Surya sendiri) tentang 'canda' Presiden seputar keuntungan Surya sebagai pemilik media dalam polling SMS ala Media Indonesia yang menempatkan rating Surya di atas presiden. Peristiwanya memang terjadi pada momen yang sama, yaitu pada saat Presiden Megawati menerima para peserta Konvensi Nasional Media Massa Se-Indonesia, dalam rangka Hari Pers Nasional. Namun, Media Indonesia mengangkat momen tersebut dengan membingkainya dalam wacana pemilu, dan bukan wacana terkait dengan kepentingan pers sendiri, walaupun sesungguhnya hari itu adalah hari bagi pers Indonesia karena bertepatan dengan momen Hari Pers Nasional 2004.

Berita kedua tentang Surya di harian Media Indonesia ditampilkan tepat seminggu setelah Sri Sultan Hamengkubuwono X menyatakan mundur dari konvensi calon presiden Golkar, sebagai wujud keprihatinan dan ekspresi moralnya terkait dengan keputusan bebas murni MA bagi Akbar Tanjung dalam kasus yang dilabeli pers sebagai "Buloggate". Berita berjudul "Surya-Sultan Adakan Pertemuan Tertutup" menampilkan nama Surya di judul berita, mendahului Sultan, sehingga tampak jelas tendensi ‘mementingkan' Surya atau 
mengonstruksi Surya dalam posisi yang penting hingga 'layak' mendahului seorang Sultan (yang oleh media lain, terutama di Yogya dan Jawa Tengah, juga kerap dikonstruksi sebagai 'sang raja' atau 'begawan' yang kuasanya melebihi presiden sekalipun!). Isi beritanya sendiri didominasi oleh pernyataan Surya seputar alasan pertemuan.

Indikasi betapa Surya dikonstruksi dalam posisi yang begitu penting, juga tampak dari pernyataan Surya yang dikutip Media Indonesia menyangkut alasan pertemuan. Surya dikutip ingin mengetahui alasan Sultan mengundurkan diri. Siapakah Surya, hingga berhak mengadakan pertemuan khusus secara tertutup untuk 'menginterogasi' Sultan seputar alasan dia mengundurkan diri? Alasan pengunduran diri Sultan, toh sudah dimuat di pelbagai media massa sejak seminggu sebelumnya. Dari amatan tertentu, pemuatan berita ini juga bisa dipandang sebagai sebuah publisitas. Ini sama halnya dengan karakteristik peristiwa itu sendiri yang tergolong sebagai event yang dikonstruksi sedemikian rupa, guna memberi atau menghadirkan ruang bagi sosok yang diberitakan, hingga media punya alasan untuk meliputnya.

Foto yang tercantum dalam berita (di halaman yang sama) adalah 2 foto seukuran pasfoto $3 \times 4$ $\mathrm{cm}$ : foto Sultan yang terkesan kalem, galau, memandang pembaca, terletak di sebelah kanan. Foto Surya diletakkan di sebelah kiri, dalam ekspresi senyum ceria, tampak optimis. Surya difoto dari samping, matanya tidak menghadap langsung ke arah pembaca, sehingga sulit membaca 'bahasa mata'nya. Jangan-jangan, ini gara-gara mata disinyalir punya bahasa yang menembus tirai-tirai kejujuran dan ketulusan!

\section{Maret: Pengusaha, Media, dan Gelar Tuanku Johan Pahlawan}

Bulan Maret, pemunculan berita tentang Surya hanya diamati sebatas hingga 10 Maret 2004. Kendati rentang pengamatannya tergolong singkat, terlihat jelas tendensi meningkatnya intensitas pemberitaan seputar Surya menjelang dimulainya masa kampanye pemilu, dan kian dekatnya pelaksanaan pemungutan suara. Ini terlihat dari berita-berita di bulan Maret.

Pada minggu pertama, Surya tampil dua kali di Media Indonesia. Berita pertama, dimuat di halaman pertama, melaporkan peluncuran program "The Election Channel" Metro TV sekaligus penandatanganan $M o U$ Metro $T V$ dengan 5 stasiun televisi internasional, yaitu $A B S \_C B N$ Broadcast (Filipina), CCTV(China), VOA-Broadcasting Board of Governor US Internasional Broadcast (AS), Seven Network (Australia) dan AlJazzera Channel (Qatar). Berita tersebut mengiringi foto Surya berjabatan tangan dengan salah satu undangan istimewa: Susilo Bambang Yudhoyono.

Berita kedua, mengangkat momen pemilihan Ketua Kadin Indonesia, yang dimanfaatkan lagilagi untuk publisitas Surya. Setidaknya, indikasi ini terlihat dari penokohan Surya sebagai tokoh penting dan dominan dalam pertemuan tersebut. Pada foto, misalnya, Media Indonesia memilih menampilkan foto Surya yang tampak berbincang serius dengan Sofjan Wanandi. Judul foto cukup provokatif: "Capres Dunia Usaha”. Judul semacam ini mengesankan relasi "Surya" dengan "Capres" dalam hubungan petanda-penanda. Membaca judul ini, terkesan adanya upaya penokohan Surya sebagai Capres yang didukung oleh kalangan industri dan perekonomian, walaupun kenyataannya isi caption foto mengabarkan diskusi yang membahas misi dan visi dalam menanggulangi permasalahan di Indonesia dari perspektif pengusaha.

Judul beritanya sendiri, yang dimuat di halaman 16, juga tak kalah provokatif dengan subtitle foto yang dimuat di halaman 2 tadi. Berita berjudul "Pengusaha Mampu Pimpin Negara" lagilagi menunjukkan relasi petanda-penanda "Surya" dengan "Capres," kali ini dalam bentuk "Pengusaha" dan "Negara". Sebuah permainan tanda yang menarik, yang memperlihatkan politik penokohan Surya yang kali ini dikonstruksi sebagai pengusaha yang layak menjadi pemimpin negara.

Pada minggu kedua, selama tiga hari berturutturut Surya muncul di harian Media Indonesia: 
hari Senin (8 Maret 2004) Surya muncul di halaman 17 pada berita berjudul "Surya Diberi Gelar Tuanku Johan Pahlawan”. Esoknya, Selasa (9 Maret 2004), Surya muncul dalam bentuk foto berjudul "Memasang Saluak"-foto ini adalah kelanjutan berita pertama, dan lagi-lagi bisa dibaca sebagai strategi 'memperpanjang' terpaan Surya pada pembaca. Rabu (10 Maret 2004), Surya muncul di halaman pertama pada berita berjudul "Surya Paloh Sesalkan Kebijakan DPP Golkar."

Ditinjau dari segi tema, hanya satu saja yang terkait dengan Pemilu, yaitu berita terakhir yang memuat tanggapan Surya Paloh atas kebijakan DPP Golkar yang membatasi ruang kampanye bagi capres Golkar selain Akbar Tanjung. Berita dan foto lain tidak terkait dengan pemilu: tema berita maupun foto yang dimuat pada hari yang terpisah itu mengabarkan fakta peristiwa penganugerahan gelar Tuanku Johan Pahlawan oleh para pemuka Adat Pagaruyung bagi Surya Paloh, atas kepeduliannya melindungi dan mengembangkan budaya Minang.

Berita hari Senin sepenuhnya menceritakan detail peristiwanya: mulai dari musyawarah adat, pertimbangan pemberian gelar, hingga laporan kedatangan Surya dengan helikopter di Dharmasraya. Kutipan kalimat Surya hanya muncul di paragraf-paragraf terakhir, berisi tanggapan dan janji Surya bagi masyarakat Dharmasraya, setelah mendapatkan gelar tersebut. Foto di hari Selasa menampilkan Surya dan Yang Dipertuan Agung Muhammad Thaib sebagai center of attention: Surya dalam busana Pagaruyung tengah membungkuk menerima pemasangan saluak (peci adat) sebagai simbol penganugerahan gelar Tuanku Johan Pahlawan. Mereka berdua dikelilingi para pemuka adat lain sebagai latar foto.

Apabila dikaitkan dengan latar kepentingan, yaitu kepentingan Surya dalam pemilu, semua berita di bulan Maret dapat dikategorikan 'bukan sekadar berita', tetapi dapat dibaca pula sebagai upaya Media Indonesia mengonstruksi sosok Surya Paloh dalam opini favourable - yaitu, dalam frame-frame positif untuk menggiring atau mengerangka publik agar membangun opini positif terhadap subyek. Momen penganugerahan gelar bagi Surya jelas merupakan publisitas tersendiri untuk dirinya. Sedangkan dalam pemberitaan menyoal tanggapan Surya yang menyesalkan kebijakan Golkar, terlihat indikasi 'menokohkan' atau menampilkan Surya sebagai tokoh penting dalam panggung politik: Surya dalam berita ini diberi porsi yang banyak sekali selaku komentator politik. Sosok maupun pernyataan-pernyataannya mendominasi isi pemberitaan.

\section{Surya dan Para "Newsmaker"}

Orang penting membuat berita. Orang yang ada di sekitar newsmaker besar kemungkinan juga akan kecipratan popularitas sang newsmaker. Kecenderungan semacam ini terlihat dalam berita seputar Surya Paloh. Mari kita lihat satu persatu.

Di bulan Januari, relatif tidak ada berita yang cukup 'hot' dalam menokohkan seseorang. Pemberitaan umumnya berkisar pada topik-topik persiapan Pemilu, dan kinerja KPU. Tidak ada tokoh yang terlalu mendominasi, paling banter Presiden. Surya, dalam momen Hari Pers Nasional terlihat tampil bersama Presiden. Karena tidak ada tokoh yang terlalu mendominasi pemberitaan, Surya menampilkan diri bersama Presiden, yang relatif akan selalu jadi tokoh nomor satu, manakala tidak ada sosok kontroversial lain.

Pola berdampingan dengan newsmaker diulang Surya pada Februari. Di bulan ini, tokoh pembuat berita adalah Akbar Tandjung yang lolos dari jerat hukum MA dalam kasus "Buloggate," dan Sri Sultan Hamengkubuwono X yang mengundurkan diri dari pencalonan kandidat presiden Partai Golkar usai jatuhnya vonis kontroversial MA tersebut. Surya bisa saja mendekati Akbar Tanjung, tapi langkah semacam ini cukup berisiko bagi upaya pencitraan diri Surya secara positif. Dengan cerdik Surya lalu memanfaatkan momen mundurnya Sri Sultan yang menghebohkan dengan merancang pertemuan eksklusif di Yogya. Momen itu tidak terlalu istimewa dan bisa dikatakan tidak menghasilkan suatu pemikiran yang cerdas dan signifikan dalam mengubah nasib bangsa. Isinya hanya berkisar seputar dukungan Surya pada keputusan Sultan 
yang didasari pertimbangan moralitas. Namun, ketika berita tersebut dimuat di halaman 1, Media Indonesia mengesankan seolah momen ini merupakan peristiwa nasional yang menentukan nasib bangsa lewat konspirasi dua tokoh penting yang sama-sama punya concern moral. Padahal, peristiwa itu bisa dibaca sebagai momen yang dirancang untuk publisitas Surya.

Di bulan Maret, Susilo Bambang Yudhoyono yang berkonflik dengan Presiden (dan Mr. President-Taufik Kiemas) menjadi the newsmaker bulan ini. Puncaknya adalah ketika Susilo memutuskan mundur dari jabatan selaku Menko Polkam. Beberapa hari sebelum Susilo mundur, Media Indonesia dengan jeli memanfaatkan konflik tersebut dengan mengekspos Surya yang dikemas dalam satu berita dengan Susilo pada foto berita 2 Maret 2004. Peristiwanya sendiri tak lebih dari launching kerjasama Metro TV dengan lima stasiun televisi asing untuk menayangkan berita Pemilu Indonesia 2004, yang dikemas Metro TV dalam program The Election Channel. Surya lagilagi memanfaatkan momen tersebut untuk publisitas dirinya. Secara menyolok, di halaman pertama Media Indonesia terbitan Selasa, 2 Maret 2003, Surya tampil dalam foto berukuran besar (15 $\mathrm{x} 18 \mathrm{~cm})$. Foto yang dijadikan headline itu merekam adegan Surya bersalaman dengan newsmaker bulan ini, Susilo Bambang Yudhoyono, yang diundang sebagai salah satu tamu dalam acara launching program televisi tersebut.

Maka, apakah yang dapat disimpulkan dari rangkaian berita yang mengangkat sosok Surya Paloh dalam diskursus pemberitaan Media Indonesia selama masa-masa Pemilu kali ini? 'Penafsiran' atau 'pembacaan' tanda-tanda yang muncul dalam teks, foto, berita, maupun iklan seputar Surya Paloh, akhirnya menghasilkan kesimpulan yang memperkuat praduga: bahwa di balik berita tentang Surya Paloh, yang ada hanyalah upaya merekonstruksi karakter dan citra positif seorang Surya Paloh dalam kepentingannya selaku salah satu kandidat calon presiden Indonesia. Event beritanya sendiri sebagian besar tidaklah alamiah, atau penting secara substansial. Apa yang dimunculkan Media Indonesia dalam pemberitaan seputar Surya Paloh, dengan demikian, tak lebih dari semacam teater media yang mementaskan adegan-adegan public relations events untuk mendongkrak popularitas dan pencitraan tokoh utamanya.

\section{Daftar Pustaka}

"Pers Harus Galang Solidaritas". Berita HU Media Indonesia edisi Sabtu, 24 Januari 2004.

"Tidak Relevan Dikotomi Parpol Terhadap SARA". Berita HU Media Indonesia edisi Kamis, 29 Januari 2004.

"Media Massa Dunia Berperan Besar: Memerangi Penyebaran AIDS”. Berita HU Media Indonesia edisi Kamis, 29 Januari 2004.

"Presiden Heran Terhadap Wacana Koalisi”. Berita HU Media Indonesia edisi Rabu, 11 Februari 2004

"Surya-Sultan Adakan Pertemuan". Berita HU Media Indonesia edisi Sabtu, 21 Februari 2004.

"Metro TV Gandeng 5 TV". Berita HU Media Indonesia edisi Selasa, 2 Maret 2004.

"Capres Dunia Usaha”. Berita HU Media Indonesia edisi Jumat, 5 Maret 2004.

"Pengusaha Mampu Pimpin Negara". Berita HU Media Indonesia edisi Jumat, 5 Maret 2004.

"Surya Diberi Gelar Tuanku Johan Pahlawan". Berita HU Media Indonesia edisi Senin, 8 Maret 2004 
